\title{
REVIEWS
}

\section{Host-pathogen interactions in urinary tract infection}

\author{
Greta R. Nielubowicz and Harry L.T. Mobley
}

\begin{abstract}
The urinary tract is a common site of bacterial infections; nearly half of all women experience at least one urinary tract infection (UTI) during their lifetime. These infections are classified based on the condition of the host. Uncomplicated infections affect otherwise healthy individuals and are most commonly caused by uropathogenic Escherichia coli, whereas complicated infections affect patients with underlying difficulties, such as a urinary tract abnormality or catheterization, and are commonly caused by species such as Proteus mirabilis. Virulence and fitness factors produced by both pathogens include fimbriae, toxins, flagella, iron acquisition systems, and proteins that function in immune evasion. Additional factors that contribute to infection include the formation of intracellular bacterial communities by $E$. coli and the production of urease by $P$. mirabilis, which can result in urinary stone formation. Innate immune responses are induced or mediated by pattern recognition receptors, antimicrobial peptides, and neutrophils. The adaptive immune response to UTI is less well understood. Host factors TLR4 and CXCR1 are implicated in disease outcome and susceptibility, respectively. Low levels of TLR4 are associated with asymptomatic bacteriuria while low levels of CXCR1 are associated with increased incidence of acute pyelonephritis. Current research is focused on the identification of additional virulence factors and therapeutic or prophylactic targets that might be used in the generation of vaccines against both uropathogens.
\end{abstract}

Nielubowicz, G. R. \& Mobley, H. L. T. Nat. Rev. Urol. 7, 430-441 (2010); published online 20 July 2010; doi:10.1038/nrurol.2010.101

\section{Introduction}

The urinary tract is one of the most common sites of bacterial infection in humans. ${ }^{1}$ Lower urinary tract infections (UTIs), such as cystitis, are typically characterized by symptoms including frequency, urgency, and dysuria. ${ }^{2}$ If left untreated, these infections can progress to an upper UTI, known as acute pyelonephritis or kidney infection, which can be associated with additional symptoms such as fever, nausea, vomiting, and flank pain. These infections also carry the risk of possible progression to bacteremia. An estimated $40 \%$ of women and $12 \%$ of men will experience a symptomatic UTI during their lifetime, and approximately a quarter of affected women will suffer recurrent UTI within 6-12 months. ${ }^{3}$ Infants and children are also susceptible to UTI. Febrile UTIs in children tend to be associated with vesicoureteral reflux and the potential for renal scarring. Pediatric UTI might predispose patients to adult disease. ${ }^{4}$ In 2006 , UTIs were the cause of more than 11 million physician visits, 1.7 million emergency room visits, and almost half a million hospitalizations; the societal cost of these infections is 3.5 billion dollars annually in the US alone. ${ }^{5,6}$

UTIs can be classified as uncomplicated or complicated. Uncomplicated infections occur in patients who are otherwise considered healthy. Complicated UTIs, on the other hand, occur in patients who are compromised in some way, for example, if they have anatomical or

Competing interests

The authors declare no competing interests. functional abnormalities in their urinary tract, are suffering from another illness, are immunocompromised, or are undergoing long-term catheterization. The vast majority of uncomplicated UTIs are caused by Escherichia coli. By contrast, complicated UTIs, especially those associated with long-term catheterization, might be polymicrobial. ${ }^{7,8}$ These infections are typically caused by Proteus mirabilis, Providencia stuartii, Morganella morganii, Klebsiella pneumoniae, E. coli, and Pseudomonas aeruginosa, among others.

This Review will focus on uropathogenic E. coli and $P$. mirabilis as representative pathogens causing uncomplicated and complicated UTI, respectively. Here, we summarize the common mechanisms of uropathogenesis utilized by uropathogenic E. coli and P. mirabilis, including adherence, toxin production, motility, metal acquisition, and evasion of host immune defenses. In addition, we will highlight differences between the two pathogens, such as the formation of intracellular bacterial communities by uropathogenic $E$. coli and the production of urease by $P$. mirabilis. The innate immune response to UTI will be outlined, including the pattern recognition receptors Toll-like receptor (TLR) 4, 5, and 11 . Host factors that impact human disease outcomes, namely TLR4 and CXC chemokine receptor type 1 (CXCR1), will also be explored. Finally, current prophylactic and treatment strategies will be briefly outlined and the need for vaccine development, as well as recent advances in the field, will be addressed. 


\section{Uropathogenesis and virulence factors}

The vast majority of UTIs are ascending infections; both E. coli and P. mirabilis can be found in the intestinal tract, which is likely to be the source of organisms infecting the urinary tract. Uropathogenic E. coli are a specific subset of extraintestinal pathogenic E. coli; that is, not all strains of E. coli are capable of causing UTI. ${ }^{9}$ By contrast, it appears that all strains of $P$. mirabilis, regardless of isolate origin, are capable of infecting the urinary tract. ${ }^{10}$ Prototypical strains of each pathogen have been sequenced: E. coli strains CFT073, ${ }^{11} 536,{ }^{12}$ UTI89, ${ }^{13}$ IAI $39,{ }^{14}$ and UMN026, ${ }^{14}$ and P. mirabilis strain HI4320. ${ }^{15}$ Horizontally acquired genetic elements have been identified in both species: uropathogenic E. coli strains have up to 13 pathogenicity island ${ }^{16-19}$ and an integrative and conjugative element was recently identified in P. mirabilis. ${ }^{20}$ Horizontal gene transfer is relevant to bacterial pathogenesis because these horizontally transferred genes often encode traits that contribute to virulence, niche specificity, or antibiotic resistance. ${ }^{21}$

Common strategies of pathogenesis employed by both uropathogenic E. coli and P. mirabilis include adherence, motility, acquisition of metals, toxin production, and immune evasion (Figure 1). For the purpose of this article, we define a virulence factor as a protein (such as a toxin) or macromolecular structure (such as a fimbria or flagellum) that contributes to the ability of the pathogen to cause disease and a fitness factor as a protein or macromolecular structure that, while not required for virulence, offers a competitive advantage during infection. Additionally, each pathogen displays unique characteristics not shared by the other, namely, uropathogenic E. coli can form intracellular bacterial communities and $P$. mirabilis synthesizes urease. Elucidation of these pathogenic mechanisms resulted from years of work carried out by many investigators. Much of this work was made possible by the availability of sequenced genomes, development of genetic screens, and use of animal models of UTI. The outcome of infection by these bacteria is dictated by the immune response to UTI and host factors that influence susceptibility to disease.

\section{Uropathogenic E. coli}

Adherence via fimbriae

Fimbriae are complex surface structures that, in general, mediate adherence of bacteria to host epithelial receptors. The recognized uropathogenic $E$. coli reference strain CFT073 encodes 13 distinct fimbrial gene clusters, including type $1, \mathrm{P}, \mathrm{F} 1 \mathrm{C}$, Dr, Auf, S, and M fimbriae. ${ }^{9,11}$ These gene clusters, or operons, encode all of the genes necessary for assembly of the fimbriae, including structural subunits as well as chaperone and usher proteins that aid in their secretion.

Type 1 fimbria, a definitive virulence factor in the murine model of ascending UTI, ${ }^{22}$ facilitates adherence to the bladder cell surface glycoprotein uroplakin and other host proteins that contain mannosides. ${ }^{23}$ Expression of type 1 fimbriae is phase variable (Box 1). Although type 1 fimbriae are almost always present in uropathogenic strains of $E$. coli isolated from human patients, the

\section{Key points}

- The urinary tract is a common site of bacterial infection

- Uropathogenic Escherichia coli and Proteus mirabilis are representative pathogens of uncomplicated and complicated urinary tract infection (UTI), respectively

- Virulence and fitness factors synthesized by both pathogens include fimbriae, toxins, flagella, iron acquisition systems, and proteins that function in immune evasion

- Additional factors that contribute to infection include the formation of intracellular bacterial communities by E. coli and the production of urease by $P$. mirabilis, which can result in urinary stone formation

- Innate immune responses are induced or mediated by pattern recognition receptors, antimicrobial peptides, and neutrophils; the adaptive immune response to UTI is less well understood

- Host factors TLR4 and CXCR1 are implicated in disease outcome and susceptibility, respectively; low levels of TLR4 are associated with asymptomatic bacteriuria; low levels of CXCR1 are associated with increased incidence of acute pyelonephritis

- Reverse vaccinology approaches are currently underway to identify potential vaccine candidates for both pathogens

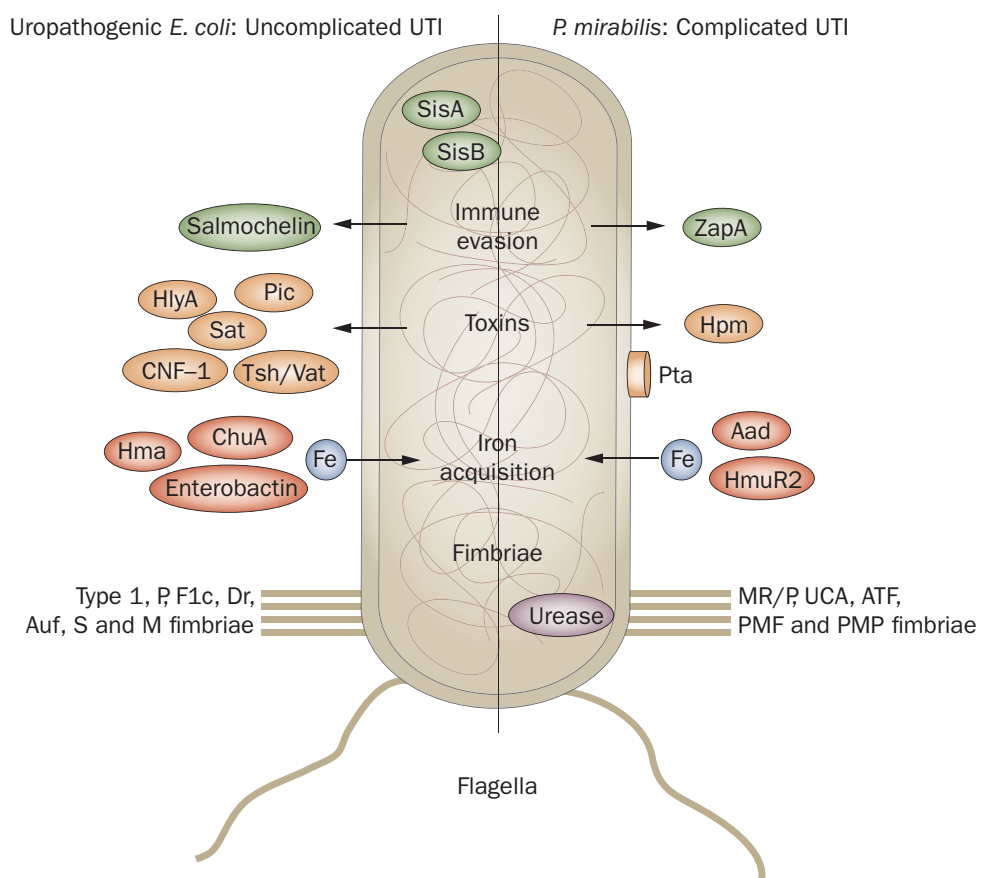

Figure 1 | Overview of uropathogen virulence factors. The left hand side of this schematic bacterial cell represents uropathogenic Escherichia coli, and the right hand side represents Proteus mirabilis. Proteins that contribute to each mechanism of pathogenesis-immune evasion, toxin production, iron acquisition, adherence, and motility - are highlighted for each pathogen. Some strains of uropathogenic E. coli strains encode the proteins SisA and SisB, which suppress the host inflammatory response during early stages of infection. P. mirabilis produces urease, which plays a role in the formation of urinary stones.

presence of type 1 fimbriae does not correlate with virulence because these fimbriae are found equally in UTI and fecal strains. ${ }^{9} \mathrm{P}$ fimbriae are associated with E. coli strains that cause acute pyelonephritis in humans, are produced and displayed during infection, and trigger a mucosal response to infection in humans, although they play only a subtle role in pathogenesis in the murine model. ${ }^{24}$ The Dr family of adhesins is comprised of 


\section{REVIEWS}

\section{Box 1 | Phase variation of fimbriae by uropathogens}

Type 1 fimbriae in uropathogenic Escherichia coli and MR/P fimbriae in Proteus mirabilis undergo phase variation. ${ }^{109,185}$ In each species, expression of these fimbrial operons is under the control of a promoter located on an invertible element upstream of the genes of interest. When the promoter is in the correct orientation, referred to as 'on', fimbrial genes are transcribed, and fimbriae are synthesized. In the opposite orientation ('off') expression and production of fimbriae does not occur.

In uropathogenic $E$. coli, the orientation of the promoter is controlled by multiple recombinase enzymes. Two of these enzymes, FimB and FimE, are encoded upstream of the fimbrial operon. ${ }^{186}$ Two additional recombinases, IpuA and IpbA, mediate switching of the invertible element independent of FimB and FimE. ${ }^{187}$ FimB and IpuA can mediate bidirectional switching of the promoter, while FimE and IpbA can only turn expression off and on, respectively. The regulation of this process is complex, affected by a multitude of environmental factors (including $\mathrm{pH}$, osmolarity, temperature, and oxygen levels) and at least three regulatory proteins (Lrp, IHF, and H-NS). ${ }^{9}$ By contrast, there is only one recombinase, Mrpl, in P. mirabilis that acts on the invertible element containing the promoter of the MR/P fimbrial operon. ${ }^{80}$ Like expression of type 1 fimbriae in uropathogenic $E$. coli, expression of MR/P fimbriae is increased under oxygen limitation. ${ }^{188}$

This type of regulation of virulence factors could be advantageous in the host, especially in the presence of antibodies directed against a protein constituent of MR/P or type 1 fimbriae. Bacteria with their promoters in the 'on' position that are expressing fimbrial genes could be targeted, whereas bacteria with their promoters in the 'off' position would not be recognized by these antibodies, essentially escaping this mechanism of the host defense.

\section{Box 2 | Coordinated regulation of motility and adherence}

In general, fimbriae mediate adherence and flagella mediate motility. Both adherence and motility are important pathogenic traits, but they have apparently opposing functions. It has been proposed that one bacterium should not be simultaneously adherent and motile. Thus, it is hypothesized that regulation of these traits must be coordinated; indeed, proteins have been identified in both uropathogenic Escherichia coli and Proteus mirabilis that seem to function in this way.

Sequencing of the MR/P operon in P. mirabilis revealed the presence of a transcriptional regulator, MrpJ, at the $3^{\prime}$ end of the fimbrial operon.

Overexpression of MrpJ led to a reduction in the expression of flagellin protein (FlaA), production of flagella, and motility. ${ }^{189,190} \mathrm{MrpJ}$ appears to bind to the promoter of the $f \mathrm{IhDC}$ operon, which encodes the so-called 'master regulator' of flagellar motility, FlhDC. Interestingly, the genome sequence of $P$. mirabilis HI432O revealed the presence of $14 \mathrm{MrpJ}$ paralogs, most of which repress motility when overexpressed. ${ }^{15,190}$ At least one of these proteins binds to the fIhDC promoter, suggesting this mechanism might be shared by at least some of these MrpJ paralogs. ${ }^{190}$ Based on the sequences of these proteins, a conserved sequence was identified, and most residues in this conserved sequence seem to be necessary for the function of MrpJ.190

The 3' end of the P fimbrial operon of uropathogenic E. coli encodes a protein with similar function to MrpJ, PapX, which represses production of flagella and motility when overexpressed. ${ }^{191} \mathrm{PapX}$ also functions at the transcriptional level, binding as a repressor to the promoter sequence of flhDC in uropathogenic E. coli. ${ }^{191}$

surface structures (both fimbrial and afimbrial) that bind to the bladder epithelium and type IV collagen on basement membranes. ${ }^{25}$ Dr adhesins are associated with cell invasion in vitro and contribute to pathogenesis in animal models of UTI. ${ }^{26,27}$ F1C fimbriae are expressed in vivo during human UTI, but their role in pathogenesis is unknown. ${ }^{28}$ Auf fimbriae are expressed by uropathogenic E. coli found in the urine of infected mice and are antigenic, but they play no apparent role in colonization of the murine urinary tract. ${ }^{29}$ In addition to these fimbrial adhesins, the nonfimbrial adhesin UpaG is an autotransporter that promotes cell aggregation and the formation of biofilms and mediates adhesion to human bladder epithelial cells. However, UpaG is not required for colonization. ${ }^{30}$ These various fimbriae encoded by uropathogenic E. coli bind to different receptors and are therefore speculated to aid in colonization of different areas in the host urinary tract.

Toxins

Three main types of toxin are produced by uropathogenic E. coli: hemolysin, cytotoxic necrotizing factor 1 (CNF1), and secreted autotransporter toxins. Hemolysin, encoded by the hlyCABD operon, is a prototypical calcium-dependent repeats-in-toxin secreted protein that is found more commonly in uropathogenic strains of $E$. coli than fecal strains. ${ }^{31}$ This toxin inserts into host cell membranes and is active against many cell types, including uroepithelial cells. ${ }^{32,33}$ Hemolysin, which is also implicated in invasion, stimulates cytokine production and leads to an inflammatory response. ${ }^{34,35}$ Although hemolysin is not required for colonization in experimental UTI, it does contribute to virulence because it is responsible for epithelial damage and bladder hemorrhage in vivo and has been implicated in causing renal damage and increasing risk for septicemia. ${ }^{36,37}$

CNF1 activity leads to constitutive activation of members of the Rho family of GTP-binding proteins, resulting in cytoskeleton rearrangements in host cells. ${ }^{38,39}$ CNF1 has been implicated in adherence to and invasion of host cells. ${ }^{40,41}$ This toxin also causes apoptosis of bladder cells, which might stimulate their exfoliation in vivo, thereby exposing underlying tissue. ${ }^{42} \mathrm{CNF} 1$ is not required for infection, but might be a fitness factor. ${ }^{43,44}$ In addition, CNF1-positive strains cause more inflammation than strains lacking this toxin. ${ }^{44}$

Three autotransporter toxins (Sat, Pic, and Tsh) have been characterized in uropathogenic E. coli and six additional autotransporters (not including UpaG, described above) have been predicted but remain uncharacterized. ${ }^{11,45}$ Sat (secreted autotransporter toxin) is a serine protease that mediates cytopathic effects on bladder and kidney cell lines in vitro and elicits tissue damage and an immune response in infected mice. ${ }^{46} \mathrm{Pic}$, another autotransporter with serine protease activity, is expressed during infection but is neither required nor advantageous for colonization. ${ }^{45,47}$ The autotransporter Tsh (also referred to as Vat [vacuolating autotransporter toxin] in CFT073), which lacks detectable serine protease activity, is expressed during infection in mice ${ }^{47}$ but is not required for colonization (E. C. Hagan and H. L. T. Mobley, unpublished work).

\section{Flagella-mediated motility}

Much like adherence, bacterial motility is another trait often associated with virulence of bacterial pathogens (Box 2). Motility is mediated by complex surface structures called flagella. Like many pathogens, uropathogenic E. coli is capable of flagella-mediated motility and flagella contribute to the fitness of uropathogenic E. coli during UTI. ${ }^{48,49}$ Flagellar genes are poorly expressed 
during chronic uropathogenic E. coli infection in mice, where they are generally downregulated in vivo compared with their expression during culture in rich laboratory medium. ${ }^{50}$ However, the synthesis of flagella appears to be tightly regulated and coincides with ascension of bacteria from the bladder to the kidneys in mice. Thus, flagella contribute to ascending $E$. coli infection..$^{51}$

\section{Metal acquisition}

Iron, an essential nutrient for all living things, is sequestered by the host, and successful bacterial pathogens must have the means to acquire it. Uropathogenic E. coli is no exception and the CFT073 genome contains at least 10 characterized iron uptake systems and several putative transporters. ${ }^{11}$ Uptake of heme, enterobactin, and other siderophores contribute to the fitness of uropathogenic E. coli during infection, but because of the functional redundancy of iron acquisition systems, no single system is absolutely required for virulence. ${ }^{52-56}$

Much like iron, zinc is an essential nutrient, and the importance of zinc acquisition has recently been demonstrated for a number of human pathogens. Indeed, the high-affinity zinc transport system ZnuACB was shown to contribute to the fitness of uropathogenic E. coli during experimental UTI. ${ }^{57}$

\section{Strategies for evading host defenses}

In addition to colonizing the host and damaging surrounding tissue, a hallmark of pathogens is the ability to avoid the host immune response. For example, as noted above, iron is a critical nutrient that must be acquired by uropathogenic E. coli during infection, and the siderophore enterobactin represents one mechanism of iron acquisition. However, the host protein lipocalin-2, which is expressed and released by neutrophils, specifically binds to and sequesters enterobactin, thereby rendering it unable to supply uropathogenic $E$. coli with iron. ${ }^{58}$ Interestingly, uropathogenic E. coli is capable of modifying enterobactin by glycosylation, and this modified enterobactin, known as salmochelin, is not recognized and sequestered by lipocalin-2 (Figure 2). Thus, uropathogenic E. coli that synthesize salmochelin escape the host defense mechanism mediated by lipocalin-2..$^{59,60}$

Uropathogenic E. coli also synthesize factors that inhibit cytokine responses ${ }^{61-63}$ and enhance tolerance to reactive oxygen and nitrogen species. ${ }^{64-67}$ Extracellular polysaccharides have also been implicated as contributing factors to evading host defenses, but definitive roles for these various surface molecules during UTI are not yet clear. ${ }^{9}$ Additionally, some uropathogenic E. coli strains encode the proteins SisA and SisB, which suppress the host inflammatory response during early stages of infection. A strain of uropathogenic E. coli in which functional copies of these genes were deleted caused significantly more inflammation during experimental infection and was more easily cleared from the host than the wild-type strain. ${ }^{68}$ In addition, the complement component C3 can be bound by uropathogenic E. coli, which can then enter epithelial cells via C3 receptors. ${ }^{69}$ Finally, phase variation of type 1 fimbrial genes might contribute to the ability of

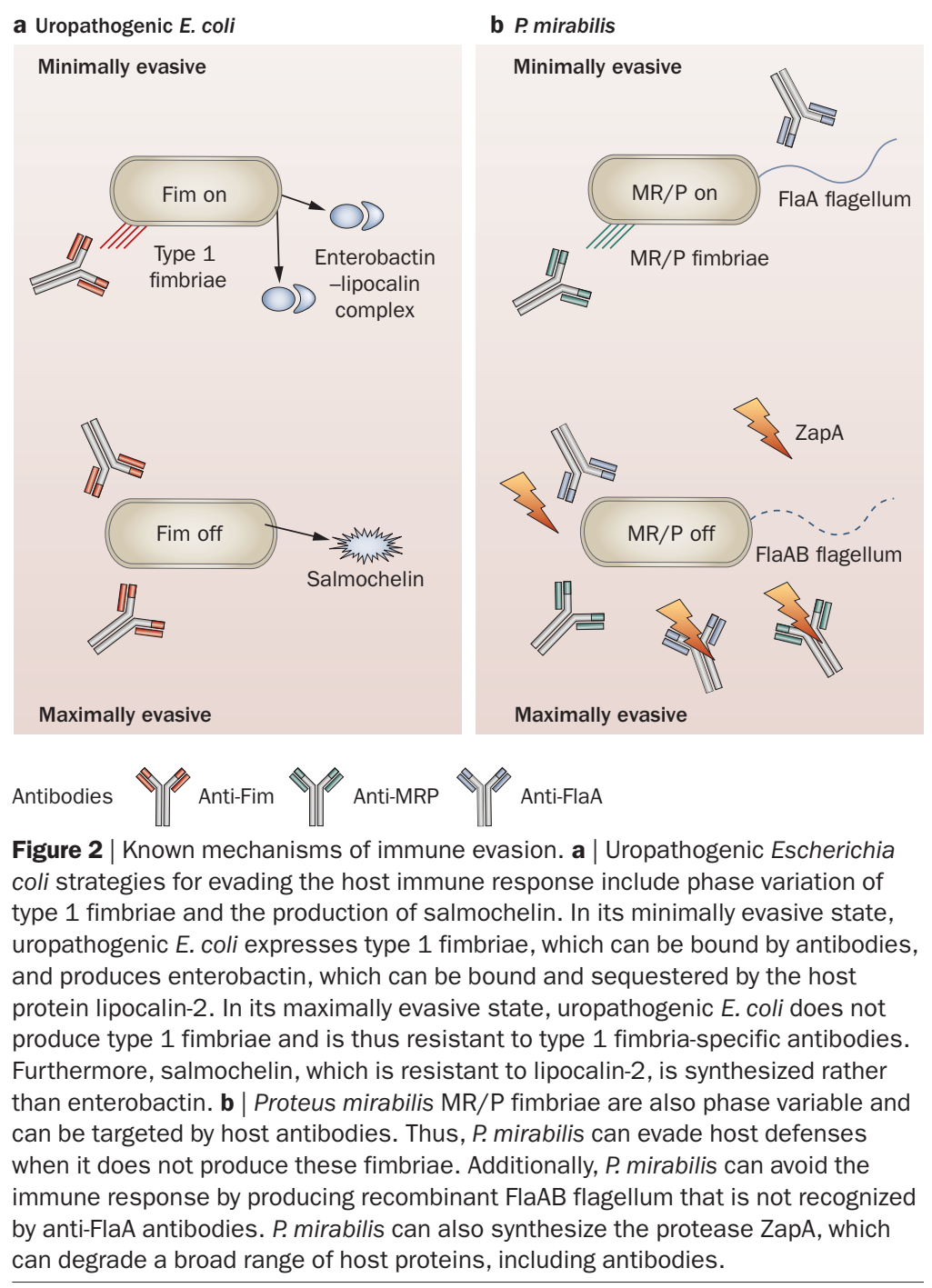

uropathogenic E. coli to avoid detection by the immune system (Box 1).

\section{Intracellular bacterial communities}

Uropathogenic E. coli are capable of forming intracellular bacterial communities (IBCs) and quiescent intracellular reservoirs (QIRs). ${ }^{70}$ IBCs have been identified in experimentally infected mouse bladders and in voided uroepithelial cells collected from human patients. ${ }^{71,72}$ IBCs appear to be the result of clonal invasion of bladder epithelial cells. Because they remain intracellular in what are proposed to be biofilm-like structures, IBCs are protected from components of the host immune response, including neutrophils and antibiotics. Thus, this mechanism might contribute to the recalcitrance of uropathogenic E. coli UTIs to antibiotic therapy. ${ }^{73}$ IBCs and QIRs might also contribute to the recurrence of UTIs owing to bacteria fluxing out of infected host cells and seeding new invasive events. ${ }^{74}$ However, it is currently difficult to pinpoint whether the source of recurrent infections is intestinal colonization, vaginal colonization, or intracellular bacteria within the urinary tract. 


\section{P. mirabilis}

Adherence via fimbriae

The sequencing and annotation of $P$. mirabilis HI4320 revealed that this strain can potentially express a diverse array of fimbriae. The genome predicts 17 distinct fimbrial operons and 13 additional orphan fimbrial genes not associated with complete operons. ${ }^{15}$ Of these, only a handful have been studied: mannose-resistant Proteuslike (MR/P), uroepithelial cell adhesin (UCA; also called NAF for nonagglutinating fimbriae), ambient temperature fimbriae (ATF), Proteus mirabilis fimbriae (PMF), and Proteus mirabilis P-like fimbriae (PMP). ${ }^{75}$

Perhaps the best understood are MR/P fimbriae, which are synthesized in vivo, elicit a strong immune response during infection, and have been implicated in autoaggregation and biofilm formation. ${ }^{76-78}$ Although not absolutely required, $\mathrm{MR} / \mathrm{P}$ fimbriae contribute to virulence. ${ }^{79,80}$ UCA fimbriae facilitate binding to uroepithelial cells and bind to host factors such as asialo$\mathrm{GM}_{1}$, asialo- $\mathrm{GM}_{2}$, lactosyl ceramide, and galectin-3. ${ }^{81-83}$ However, the role of UCA fimbriae in the virulence of P. mirabilis in vivo has not been reported. PMF fimbriae represent a fitness factor during experimental UTI, but their exact role in adherence to host cells is unclear. ${ }^{84,85}$ ATF are optimally expressed at ambient temperature, as opposed to host body temperature, ${ }^{86}$ so perhaps it is not surprising that these fimbriae do not play a role in colonization of the urinary tract. ${ }^{87}$ PMP fimbriae were identified from a canine UTI isolate, but the genes encoding this fimbria have also been found in at least one human clinical isolate. ${ }^{15,88}$ However, their role during UTI has not been reported. Given the important role of many fimbriae on the pathogenic processes, it will be interesting to see what roles, if any, the other potential fimbriae encoded in the genome of $P$. mirabilis HI4320 have during UTI.

\section{Toxins}

Two toxins encoded by $P$. mirabilis have been characterized: hemolysin (HpmA) and Proteus toxic agglutinin (Pta). HpmA is secreted from the bacterium (in a process mediated by HpmB) and has calcium-independent hemolytic and cytotoxic activities. ${ }^{89,90}$ Pta, an autotransporter with subtilisin-like serine protease activity, remains anchored at the bacterial surface and mediates autoagglutination of bacteria as well as toxicity against cultured human bladder and kidney cells in vitro. ${ }^{91} \mathrm{HpmA}$ and Pta both contribute to tissue damage observed during infection. ${ }^{92}$ Pta contributes to the ability of $P$. mirabilis to colonize the urinary tract; HpmA does not. ${ }^{91,92}$

\section{Flagella-mediated motility}

Perhaps the most defining characteristic of P. mirabilis is swarming motility, a specialized form of flagellamediated movement that requires the differentiation of cells into an elongated morphotype teeming with flagella. ${ }^{93}$ These elongated cells seem to be in the minority during infection. ${ }^{94}$ However, P. mirabilis is capable of swarming across the surface of urinary catheters. ${ }^{95}$ Perhaps this phenomenon represents the mechanism by which bacteria gain access to the host, which suggests that this morphotype might be encountered, at the very least, during early stages of human infection.

The roles of swarming and swimming motility during infection are difficult to distinguish because both types of motility are mediated by flagella. Strains lacking flagella are weakened in the murine model, implying a role for flagella during ascending UTI. ${ }^{96}$ However, a strain of $P$. mirabilis lacking flagella has been isolated from a human patient, suggesting that flagella are not strictly required for virulence of this uropathogen. ${ }^{97}$

\section{Metal acquisition}

Historically, it was thought that $P$. mirabilis did not produce any of the siderophores known to be produced by other members of the Enterobacteriaceae family. ${ }^{98}$ However, sequencing and annotation of HI4320 revealed that this strain of $P$. mirabilis encodes two seemingly complete siderophore synthesis operons. ${ }^{15}$ Careful reexamination of siderophore synthesis has revealed that $P$. mirabilis does, in fact, produce siderophores, and the structure of these siderophores is currently under investigation (S. Himpsl and H. L. T. Mobley, unpublished work). Additionally, P. mirabilis can utilize heme and hemin via the receptor HmuR2, which contributes to the fitness of $P$. mirabilis during experimental UTI. ${ }^{99}$

$P$. mirabilis produces $\alpha$-hydroxyisovaleric acid, which has been suggested to function in iron acquisition..$^{98}$ a-keto acids, formed by the deamination of amino acids by the enzyme amino acid deaminase (Aad), can also be utilized as lower affinity siderophores by $P$. mirabilis. ${ }^{100,101}$ Surprisingly, the aad gene is not affected by iron concentrations, leading to speculation that perhaps iron acquisition is not the sole function of Aad. ${ }^{101}$ Interestingly, it has been speculated that Aad might be essential because multiple attempts to generate an isogenic mutant lacking aad were unsuccessful. ${ }^{101}$ Thus, the role of Aad during infection, or even its unequivocal role in iron uptake, has not been confirmed.

Similarly to uropathogenic E. coli, the ZnuACB highaffinity zinc transport system has recently been shown to be a fitness factor for P. mirabilis. This system contributes to, but is not required for, experimental UTI. ${ }^{102}$

\section{Strategies for evading host defenses}

At least three known mechanisms utilized by $P$. mirabilis contribute to immune evasion during infection (Figure 2). One is the production of ZapA, a zinc metalloprotease that is capable of cleaving a broad range of host proteins, including serum and secretory IgA1, IgA2, and IgG, complement proteins, and antimicrobial peptides. ${ }^{103}$ ZapA activity has been detected in the urine of infected patients and contributes to the ability of $P$. mirabilis to colonize the urinary tract. ${ }^{104,105}$

Another mechanism requires recombination of two independent copies of flagellin genes, flaA and flaB. ${ }^{106}$ FlaA is the predominate version of flagellin expressed by $P$. mirabilis; the flaB locus is normally silent. ${ }^{107}$ However, upon recombination of these genes, $P$. mirabilis produces flagella that are antigenically distinct 
and therefore potentially capable of subverting the immune response. ${ }^{107,108}$

Lastly, MR/P fimbriae are capable of undergoing phase variation, which might facilitate immune response avoidance (Box 1). ${ }^{109}$

\section{Urease production}

One of the hallmarks of UTI caused by P. mirabilis is urolithiasis, the production of stones in the urinary tract. The formation of these stones is the result of activity of the bacterial enzyme urease, which hydrolyzes urea into ammonia and carbonate (Figure 3). The production of ammonia significantly raises the local $\mathrm{pH}$, resulting in the precipitation of ions that are normally soluble in urine. These stones, such as magnesium ammonium phosphate (struvite), can block the flow of urine through catheters and result in renal scarring owing to calculus formation within the renal pelvis. Additionally, bacteria can be found within these urinary stones, where they are thought to be protected from host defenses and antibiotic treatment. ${ }^{110}$ Indeed, following antibiotic therapy, bacteria from the stones can reseed the urine.

\section{Overview of host defenses}

The vast majority of work characterizing host defenses against UTI has focused on uropathogenic E. coli infections. Less is known about the response to P. mirabilis, but because both organisms affect the same organ system, aspects of the host defense might be similar in response to both pathogens.

\section{Urine flow and cell exfoliation}

Organisms infecting the urinary tract must overcome the mechanical force of the flow of urine. Paradoxically, the shear stress of urine flow enhances the binding interactions of FimH (the tip adhesin of type 1 fimbria), and therefore adherence of uropathogenic E. coli. ${ }^{111}$ Superficial umbrella cells in the bladder are covered with membrane proteins known as uroplakins. ${ }^{112}$ Type 1 fimbriae of uropathogenic E. coli bind to uroplakin-1a, ${ }^{113}$ triggering exfoliation of the bladder epithelium. The process of exfoliation serves to remove adherent bacteria but also allows access to underlying tissue that is normally not exposed, despite rapid differentiation of these underlying cells into superficial facet cells in response to exfoliation. ${ }^{14,115}$ During uropathogenic E. coli infection, this exfoliation is the result of an apoptosis-like mechanism promoted by FimH. ${ }^{114,116}$

\section{Innate and adaptive immune responses to UTI}

These topics have been covered extensively in other review articles. ${ }^{117,118} \mathrm{~A}$ limited overview will be presented here (Figure 4).

\section{Innate immune response to UTI}

Antimicrobial peptides are short, positively charged peptides that bind to and disrupt bacterial membranes. $\beta$-defensin 1 and the cathelicidin LL-37, for example, have both been implicated in the response to UTI. ${ }^{19-121}$ As discussed above, iron is an essential nutrient that
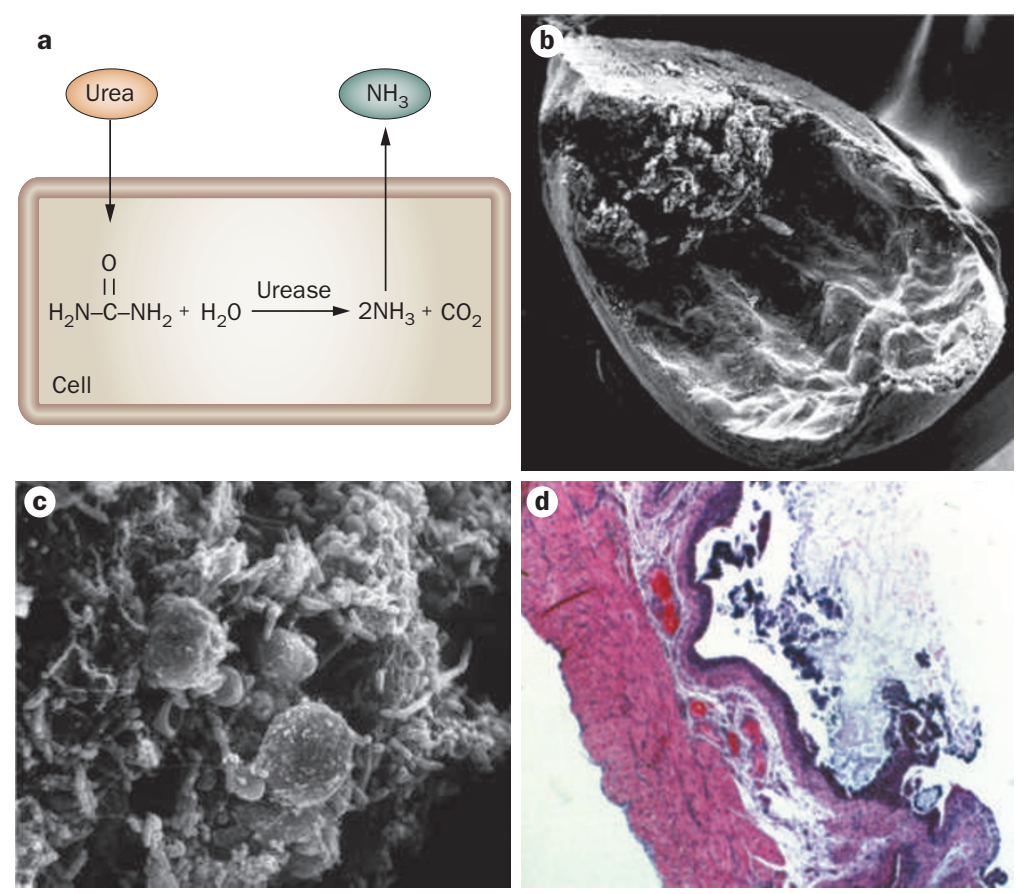

Figure 3 | Formation of urinary stones is the result of bacterial urease. a | Urease catalyzes the hydrolysis of urea into ammonia and carbonate. The production of ammonia significantly raises the local $\mathrm{pH}$, resulting in the precipitation of ions that are normally soluble in urine. $\mathbf{b}$ | Scanning electron micrograph of a segment of mouse bladder after experimental Proteus mirabilis infection. A stone can be seen at the inferior end of the bladder. c | 100-fold larger magnification of the stone shown in panel B, in which bacterial cells, erythrocytes, neutrophils, and host cell fragments are visible. d | Hematoxylin and eosin-stained section of a P. mirabilisinfected mouse bladder carrying a lumenal stone. Permission obtained from American Society for Microbiology @ Li, X. et al. Infect. Immun. 70, 389-394 (2002).

the host sequesters. This iron sequestration is mediated by factors such as lactoferrin, transferrin, and lipocalin-2. ${ }^{122}$ Tamm-Horsfall protein, also known as uromodulin, is a high-molecular-weight glycoprotein present in human urine that binds to type 1 fimbriae, thereby limiting interaction of uropathogenic $E$. coli with host receptors. ${ }^{123}$ Tamm-Horsfall protein is also effective against $P$. mirabilis. ${ }^{124}$

A large panel of cytokines and chemokines are upregulated in response to uropathogenic E. coli infection in mice. ${ }^{125}$ Most of these peak by 1 day postinfection and return to levels near baseline by 2 weeks postinfection, except for IL-17A, which was recently shown to contribute to innate clearance of uropathogenic E. coli. ${ }^{126}$ IL-8, the main neutrophil attractant in humans, is secreted by both bladder and kidney cell lines in response to uropathogenic E. coli. ${ }^{127-129}$ Indeed, neutrophils are the most rapid and robust responders to UTI and their migration to the site of uropathogenic E. coli infection in the urinary tract is dependent on IL-8. ${ }^{130-133}$

Pathogen recognition receptors, specifically TLR4 and TLR5 in humans, as well as TLR11 in mice, have been implicated in the response to UTI. By contrast, TLR2 does not appear to be required for a normal response to UTI. ${ }^{134}$ TLR4 knockout mice infected with uropathogenic E. coli have higher bacterial burdens because TLR4 is important for clearance and the inflammatory response 


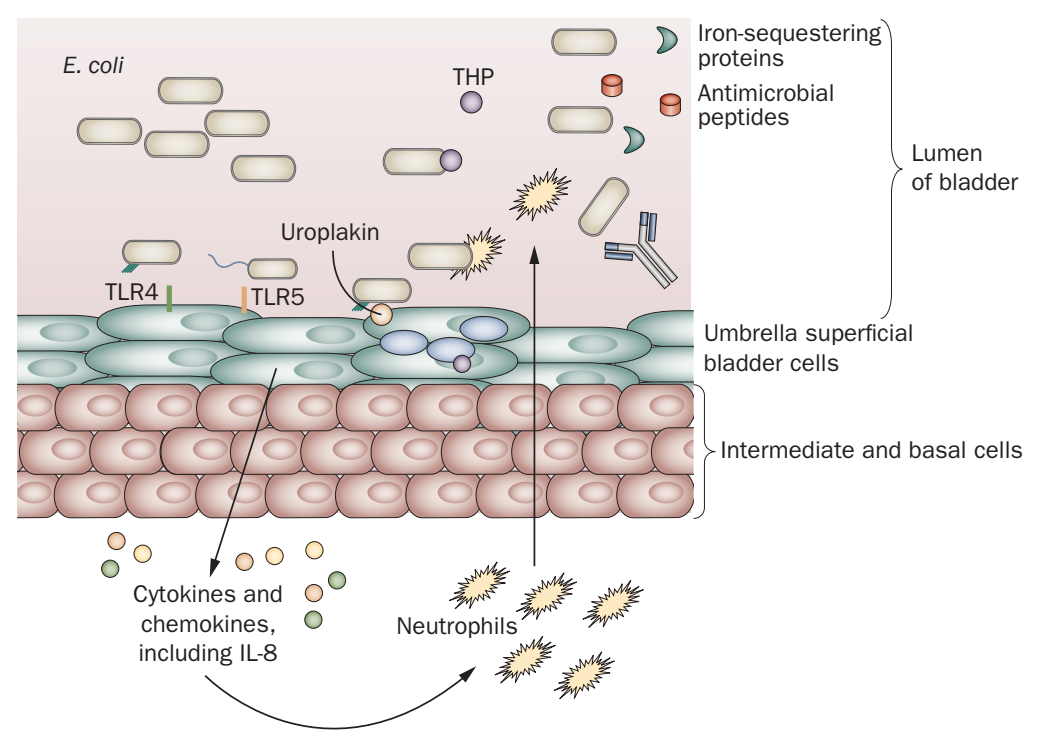

Figure 4 | Uropathogenic Escherichia coli interaction with components of the host immune system. In the lumen of the bladder, uropathogenic E. coli must face such challenges as binding by THP, attack by antimicrobial peptides (such as $\beta$-defensin 1 and the cathelicidin LL-37), and competition with host ironsequestering proteins (such as lipocalin-2, transferrin, and lactoferrin). Uropathogenic E. coli can be detected by the bladder epithelium via binding to TLR4 (mediated by either type 1 or P fimbriae), TLR5 (mediated by flagella) and uroplakin-1a (via type 1 fimbriae). These interactions with the uroepithelium result in secretion of cytokines and chemokines, including IL-8, which results in the recruitment of neutrophils to the bladder. Although not as much is known about the adaptive immune response to UTI, antibodies have been implicated in this role. Abbreviations: THP, Tamm-Horsfall protein; TLR, Toll-like receptor.

in the bladder and kidneys. ${ }^{135-137}$ TLR4 signaling can be induced by multiple mechanisms, including a $P$ fimbriaedependent and lipopolysaccharide-independent pathway ${ }^{138-140}$ and a lipopolysaccharide-dependent and type 1 fimbriae-dependent pathway. ${ }^{128,141}$ In addition, FimH can directly interact with TLR4..$^{135,142}$ Regardless of the source of stimulation, TLR4-mediated signaling results in the activation of NFKB and expression of proinflammatory genes, such as IL-6 and IL-8. ${ }^{143}$ TLR5 recognizes flagella, is involved in the response to uropathogenic E. coli infection, and results in the production of proinflammatory factors. ${ }^{144,145}$ Mice lacking TLR11 are more susceptible to uropathogenic infection; however, it appears that humans lack functional TLR11 owing to an early stop codon..$^{146}$

\section{Adaptive immune response to UTI}

In general, data regarding the adaptive immune response to UTI are limited. Results from one seminal study suggest that the protection derived from infection is antibodymediated. ${ }^{147}$ In addition, there is evidence that uropathogenic E. coli clearance is also antibody-mediated. ${ }^{148-151}$ At this point, it is unclear if the immune response is skewed toward a $\mathrm{T}_{\mathrm{H}} 1$-mediated or $\mathrm{T}_{\mathrm{H}} 2$-mediated response, and the role of $\mathrm{T}_{\mathrm{REG}}$ cells has not been elucidated.

\section{Genetic variations that influence UTI}

This topic has been reviewed thoroughly elsewhere, ${ }^{134,152}$ but a brief overview will be presented here, focusing on two host factors that can impact susceptibility and outcome of disease: TLR4 and CXC chemokine receptor type 1 (CXCR1). Susceptibility is also affected by the density of epithelial cell receptors-patients who are prone to UTI seem to have higher numbers of receptors for bacterial fimbriae. ${ }^{153}$

As described above, TLR4 signaling is important for the host response to UTI. Interestingly, infection of mice with mutations in TLR4 resulted in an asymptomatic carrier state. ${ }^{143,154}$ However, it should be noted that these mice were not spared from death following these infections. ${ }^{155}$ TLR4 might also be associated with asymptomatic infections in humans, as children with asymptomatic infections have lower expression of TLR4 mRNA and protein in neutrophils than age-matched controls. ${ }^{156}$

CXCR1, the receptor for IL-8, is essential for the migration and activation of neutrophils. In mice lacking the IL-8 receptor, infection with uropathogenic E. coli resulted in higher bacterial titers and progression to bacteremia and renal scarring than in infected wildtype mice, suggesting that functional CXCR1 plays a role in protecting the host from severe infection. ${ }^{157-159} \mathrm{In}$ human patients, CXCR1 mRNA and protein levels are significantly lower in neutrophils isolated from the blood of children who are prone to pyelonephritis. ${ }^{157}$ Further work revealed that these UTI-prone children had single nucleotide polymorphisms in their CXCR1 genes. ${ }^{160}$ In addition, CXCR1 expression was also lower in relatives of these children, suggesting that low expression, and perhaps also the resultant increased susceptibility to acute pyelonephritis, is inheritable. ${ }^{161}$

\section{Treatment and prevention of UTI}

\section{Current prophylaxis and treatment strategies}

Beyond continuous or intermittent (postcoital) antibiotic usage, current prophylactic strategies are limited to consumption of cranberry juice and, for postmenopausal women, estrogen treatment. ${ }^{162}$ The utilization of different compounds for the prevention of UTI in animal models has been reported, including the glucose analog $\mathrm{N}$-butyldeoxynojirimycin, ${ }^{163}$ forskolin, ${ }^{164}$ small molecule inhibitors ${ }^{165}$ and anti-FimH antibodies. ${ }^{166}$ None of these compounds have been tested in human UTI patients, to our knowledge. Treatment with protamine sulfate is associated with increased exfoliation of umbrella cells and, in mice, reduced bacterial burden in the bladder. ${ }^{70}$ However, this treatment caused significant discomfort in human volunteers. ${ }^{167}$ The standard treatment for UTI remains antibiotic therapy, which unfortunately can also disrupt the microbiota and result in the selection of resistant strains.

\section{Catheter-associated complicated UTIs}

More than 5 million patients are catheterized each year, and each one is at significant risk for UTI. ${ }^{168}$ The first steps to reducing the risk of these infections are to limit the use of urinary catheters, which are generally overused, and to make sure they are removed promptly when no longer medically necessary. ${ }^{168,169}$ There has been much interest in developing catheter coatings to reduce bac- 
terial colonization, but, to date, no single surface has been demonstrated to effectively prevent long-term colonization. ${ }^{168}$ Early studies employing the catheter balloon, rather than the surface of the catheter, as a reservoir for antimicrobial compounds have been encouraging. ${ }^{170}$ In addition, the probiotic use of nonpathogenic E. coli strains might prevent catheter colonization by pathogenic strains. ${ }^{171}$ Infection with urease-positive strains, such as P. mirabilis, is a further complication because urinary stones potentially serve as a reservoir for bacteria, which can rapidly colonize replacement catheters. ${ }^{172}$

\section{Vaccines to prevent UTI}

Given the large impact of these infections (on both individual patients and the health-care system) and the current lack of effective, nonantibiotic prophylactic strategies, there is much interest in the development of vaccines to prevent both uncomplicated and complicated UTIs. Different patient populations are likely to benefit from these respective vaccines. We anticipate that a uropathogenic $E$. coli vaccine could be administered to individuals who suffer from, or are at increased risk for, recurrent infections, whereas a $P$. mirabilis vaccine would be most beneficial to patients at an increased risk of developing complicated infections, including individuals with known functional or anatomical urinary tract abnormalities and patients at the onset of long-term catheterization.

\section{Uropathogenic E. coli vaccines}

Vaccines targeting uropathogenic E. coli have recently been reviewed. ${ }^{117}$ Perhaps the two most successful vaccine formulations to date are Uro-Vaxom (OM Pharma, Geneva, Switzerland), a daily oral capsule containing membrane proteins from 18 E. coli strains, and SolcoUrovac (Solco Basel AG, Birsfelden, Switzerland), a vaginal suppository containing ten heat-killed uropathogenic strains. ${ }^{173,174}$ However, there is currently no licensed uropathogenic $E$. coli vaccine available in the US and active research toward this goal is ongoing.

Historically, vaccines against uropathogenic E. coli have been directed against known virulence factors, specifically components of $\mathrm{P}$ and type 1 fimbriae. Recently, additional vaccine candidates were identified via multiple 'omics' approaches, including genomic, proteomic, and metabolomic screens. ${ }^{175}$ These approaches identified a number of protein vaccine candidates that are pathogen-specific, antigenic, surface-exposed, and expressed in vivo. Interestingly, the top candidates (those identified from multiple screens that fit all of the above criteria) were outer membrane iron receptors. Intranasal vaccination with three outer membrane iron receptors protected mice from uropathogenic E. coli-mediated UTI. ${ }^{176}$ Protection correlated with production of antigen-specific IgA in the urine and class switching from IgM to antigen-specific IgG. ${ }^{176}$ One goal of future research should be to determine if these findings will translate to human UTI patients.

\section{P. mirabilis vaccines}

Early studies showed that initial infection with $P$. mirabilis does not prevent re-infection, and heat-killed preparations do not prevent initial infection. ${ }^{177,178}$ Immunization with outer membrane preparations protected mice from renal colonization, tissue damage, and death. ${ }^{179}$ Varying degrees of protection were offered by immunization with fimbrial structural proteins MrpA, UcaA, and PmfA. ${ }^{180,181}$ One of these recent studies employed Lactococcus lactis as an antigen delivery vehicle, a novel approach in Proteus vaccinology that, in general, is a promising idea for the development of new vaccines against mucosal pathogens, since these vaccines seem to have fewer side effects than systemic vaccines. ${ }^{180}$ One of the most promising vaccines to date has been intranasal immunization with the $\mathrm{N}$-terminal domain of $\mathrm{MrpH}$, the tip adhesin of MR/P fimbriae. ${ }^{182}$ Recently, an immunoproteomic screen was performed to identify outer membrane proteins of $P$. mirabilis that can elicit an immune response in infected mice. ${ }^{183}$ Since these proteins are expressed in vivo and are exposed to the surface (where they could potentially interact with the host), they represent exciting new potential vaccine candidates. Indeed, immunization with one of these proteins, Pta, protected mice from subsequent transurethral challenge. ${ }^{92}$

\section{Conclusions}

Uropathogenic E. coli and P. mirabilis are pathogens of the urinary tract, a common site of bacterial infection in humans. Proteins that are required for, or contribute to, the virulence of each pathogen have been identified, and these discoveries have contributed to our understanding of the mechanisms of pathogenesis. Such virulence or fitness factors include fimbriae (such as type 1 and P fimbriae in uropathogenic E. coli and MR/P and UCA fimbriae in P. mirabilis) that mediate attachment to host tissues, toxins (such as hemolysins and autotransporter toxins in both species), flagella, iron acquisition systems, and proteins that function to dampen or evade the host immune response (such as SisA and SisB in uropathogenic E. coli and ZapA in $P$. mirabilis). In addition, each pathogen has some traits not shared with the other: uropathogenic E. coli is capable of forming intracellular bacterial communities, and $P$. mirabilis produces the enzyme urease, the action of which can lead to the formation of urinary stones and block the flow of urine through catheters.

To successfully colonize and persist in the host, these uropathogens must overcome host defenses mediated by the innate and adaptive immune systems. Innate responses to UTI are more well-defined than adaptive responses. Tamm-Horsfall protein, antimicrobial peptides, and iron sequestration proteins such as transferrin and lactoferrin are active in the urinary tract. TLRs can be engaged by multiple uropathogenic E. coli components, including flagella and both $\mathrm{P}$ and type 1 fimbriae. Numerous cytokines and chemokines are upregulated in response to infection; the chemoattractant IL- 8 is required for the migration of neutrophils to the infected urinary tract. Not surprisingly, deviations in components of the host immune system can impact susceptibility to, or outcome of, infection. Reduced levels of TLR 4 are associated with 
the development of asymptomatic bacteriuria, while reduced levels of CXCR1 are associated with increased susceptibility to acute pyelonephritis.

UTIs cause significant morbidity and are typically treated with antibiotics; there is currently not a licensed vaccine available in the US against uropathogenic E. coli or P. mirabilis. Thus, there has been interest in the generation of vaccines against both uropathogens. Much of current research is focused on pathogen gene and protein expression in vivo during infection of the host, with the hope of identifying additional virulence factors and therapeutic or prophylactic targets. Recently, an 'omics' approach, consisting of multiple screens, led to the identification of several uropathogenic E. coli vaccine candidates that were able to protect mice from subsequent infection. Similar screens are currently underway in P. mirabilis. These types of 'reverse vaccinology' approaches have broad appeal and have led to the successful identification of potential vaccine candidates in other human pathogens, such as Neisseria meningitidis serogroup B, Streptococcus agalactiae, and Streptococcus pneumoniae. ${ }^{184}$ In addition, further study will be required to elucidate adaptive immune responses in the urinary tract. These findings will aid understanding of the disease process and might also provide insight toward the generation of lasting immunity against uropathogens.

Review criteria
We searched for original articles on PubMed using the
search terms "urinary tract infection", “uropathogenic
E. coli", and "Proteus mirabilis". All papers identified were
English-language full-text papers. We also searched the
reference lists of identified articles for further papers.
Most cited articles were published between 1994 and
2010, but some earlier seminal studies were also
included.

1. Foxman, B. Epidemiology of urinary tract infections: incidence, morbidity, and economic costs. Dis. Mon. 49, 53-70 (2003).

2. Guay, D. R. Contemporary management of uncomplicated urinary tract infections. Drugs 68 1169-1205 (2008).

3. O'Hanley, P. in Urinary Tract Infections: Molecular Pathogenesis and Clinical Management (eds Mobley, H. L. T. \& Warren, J. W.) 405-425 (ASM Press, Washington, DC, 1996).

4. Zorc, J. J., Kiddoo, D. A. \& Shaw, K. N. Diagnosis and management of pediatric urinary tract infections. Clin. Microbiol. Rev. 18, 417-422 (2005).

5. Litwin, M. S. \& Saigal, C. S. (Eds) Urologic Diseases in America (Government Printing Office, Washington, D. C., 2007).

6. DeFrances, C. J., Lucas, C. A., Buie, V. C. \& Golosinskiy, A. 2006 National Hospital Discharge Survey. National health statistics reports; no 5. (Hyattsville, MD, 2008).

7. Hooton, T. M. et al. Diagnosis, prevention, and treatment of catheter-associated urinary tract infection in adults: 2009 International Clinical Practice Guidelines from the Infectious Diseases Society of America. Clin. Infect. Dis. 50, 625-663 (2010).

8. Nicolle, L. E. Catheter-related urinary tract infection. Drugs Aging 22, 627-639 (2005).

9. Mobley, H. L., Donnenberg, M. S. \& Hagan, E. C. EcoSal-Escherichia coli and Salmonella: Cellular and Molecular Biology (eds Böck, A. et al.) (ASM Press, Washington, DC, 2009).

10. Sosa, V., Schlapp, G. \& Zunino, P. Proteus mirabilis isolates of different origins do not show correlation with virulence attributes and can colonize the urinary tract of mice. Microbiology 152, 2149-2157 (2006).

11. Welch, R. A. et al. Extensive mosaic structure revealed by the complete genome sequence of uropathogenic Escherichia coli. Proc. Natl Acad. Sci. USA 99, 17020-17024 (2002).

12. Brzuszkiewicz, E. et al. How to become a uropathogen: comparative genomic analysis of extraintestinal pathogenic Escherichia coli strains. Proc. Natl Acad. Sci. USA 103, 12879-12884 (2006).

13. Chen, S. L. et al. Identification of genes subject to positive selection in uropathogenic strains of Escherichia coli: a comparative genomics approach. Proc. Natl Acad. Sci. USA 103, 5977-5982 (2006).
14. Touchon, M. et al. Organised genome dynamics in the Escherichia coli species results in highly diverse adaptive paths. PLoS Genet. 5, e1000344 (2009).

15. Pearson, M. M. et al. The complete genome sequence of uropathogenic Proteus mirabilis, a master of both adherence and motility. J. Bacteriol. 190, 4027-4037 (2008).

16. Sabate, M., Moreno, E., Perez, T., Andreu, A. \& Prats, G. Pathogenicity island markers in commensal and uropathogenic Escherichia coli isolates. Clin. Microbiol. Infect. 12, 880-886 (2006).

17. Oelschlaeger, T. A., Dobrindt, U. \& Hacker, J. Pathogenicity islands of uropathogenic E. coli and the evolution of virulence. Int. J. Antimicrob. Agents 19, 517-521 (2002).

18. Ye, C. \& Xu, J. Prevalence of iron transport gene on pathogenicity-associated island of uropathogenic Escherichia coli in E. coli 0157:H7 containing Shiga toxin gene. J. Clin. Microbiol. 39, 2300-2305 (2001).

19. Lloyd, A. L., Rasko, D. A. \& Mobley, H. L. Defining genomic islands and uropathogen-specific genes in uropathogenic Escherichia coli. J. Bacteriol. 189, 3532-3546 (2007).

20. Flannery, E. L., Mody, L. \& Mobley, H. L. Identification of a modular pathogenicity island that is widespread among urease-producing uropathogens and shares features with a diverse group of mobile elements. Infect. Immun. 77, 4887-4894 (2009).

21. Ochman, H., Lawrence, J. G. \& Groisman, E. A. Lateral gene transfer and the nature of bacterial innovation. Nature 405, 299-304 (2000).

22. Connell, I. et al. Type 1 fimbrial expression enhances Escherichia coli virulence for the urinary tract. Proc. Natl Acad. Sci. USA 93, 9827-9832 (1996).

23. Wu, X. R., Sun, T. T. \& Medina, J. J. In vitro binding of type 1-fimbriated Escherichia coli to uroplakins la and lb: relation to urinary tract infections. Proc. Natl Acad. Sci. USA 93, 9630-9635 (1996).

24. Lane, M. C. \& Mobley, H. L. Role of P-fimbrial-mediated adherence in pyelonephritis and persistence of uropathogenic Escherichia coli (UPEC) in the mammalian kidney. Kidney Int. 72, 19-25 (2007).

25. Westerlund, B. et al. The 075X adhesin of uropathogenic Escherichia coli is a type IV collagen-binding protein. Mol. Microbiol. 3, 329-337 (1989).
26. Goluszko, P. et al. Development of experimental model of chronic pyelonephritis with Escherichia coli 075:K5:H-bearing Dr fimbriae: mutation in the dra region prevented tubulointerstitial nephritis. J. Clin. Invest. 99, 1662-1672 (1997).

27. Das, M. et al. Hydrophilic domain II of Escherichia coli Dr fimbriae facilitates cell invasion. Infect. Immun. 73, 6119-6126 (2005).

28. Pere, A., Nowicki, B., Saxen, H., Siitonen, A. \& Korhonen, T. K. Expression of P, type-1, and type-1C fimbriae of Escherichia coli in the urine of patients with acute urinary tract infection. J. Infect. Dis. 156, 567-574 (1987).

29. Buckles, E. L. et al. Identification and characterization of a novel uropathogenic Escherichia coli-associated fimbrial gene cluster. Infect. Immun. 72, 3890-3901 (2004).

30. Valle, J. et al. UpaG, a new member of the trimeric autotransporter family of adhesins in uropathogenic Escherichia coli. J. Bacteriol. 190, 4147-4161 (2008).

31. Boehm, D. F., Welch, R. A. \& Snyder, I. S. Calcium is required for binding of Escherichia coli hemolysin (HlyA) to erythrocyte membranes. Infect. Immun. 58, 1951-1958 (1990).

32. Island, M. D. et al. Cytotoxicity of hemolytic, cytotoxic necrotizing factor 1-positive and -negative Escherichia coli to human T24 bladder cells. Infect. Immun. 66, 3384-3389 (1998).

33. Mobley, H. L. et al. Pyelonephritogenic Escherichia coli and killing of cultured human renal proximal tubular epithelial cells: role of hemolysin in some strains. Infect. Immun. $\mathbf{5 8}$ 1281-1289 (1990).

34. Trifillis, A. L. et al. Binding to and killing of human renal epithelial cells by hemolytic P-fimbriated E. coli. Kidney Int. 46, 1083-1091 (1994).

35. Uhlen, P. et al. Alpha-haemolysin of uropathogenic $\mathrm{E}$. coli induces $\mathrm{Ca}^{2+}$ oscillations in renal epithelial cells. Nature 405, 694-697 (2000).

36. Smith, Y. C., Rasmussen, S. B., Grande, K. K., Conran, R. M. \& O'Brien, A. D. Hemolysin of uropathogenic Escherichia coli evokes extensive shedding of the uroepithelium and hemorrhage in bladder tissue within the first 24 hours after intraurethral inoculation of mice. Infect. Immun. 76, 2978-2990 (2008).

37. O'Hanley, P., Lalonde, G. \& Ji, G. Alpha-hemolysin contributes to the pathogenicity of piliated digalactoside-binding Escherichia coli in the kidney: efficacy of an alpha-hemolysin vaccine in 
preventing renal injury in the BALB/c mouse model of pyelonephritis. Infect. Immun. 59, 1153-1161 (1991).

38. Boquet, P. The cytotoxic necrotizing factor 1 (CNF1) from Escherichia coli. Toxicon 39, 1673-1680 (2001).

39. Lemonnier, M., Landraud, L. \& Lemichez, E. Rho GTPase-activating bacterial toxins: from bacterial virulence regulation to eukaryotic cell biology. FEMS Microbiol. Rev. 31, 515-534 (2007).

40. Falzano, L. et al. Induction of phagocytic behaviour in human epithelial cells by Escherichia coli cytotoxic necrotizing factor type 1. Mol. Microbiol. 9, 1247-1254 (1993).

41. Hofman, P. et al. Escherichia coli cytotoxic necrotizing factor-1 (CNF-1) increases the adherence to epithelia and the oxidative burst of human polymorphonuclear leukocytes but decreases bacteria phagocytosis. J. Leukoc. Biol. 68, 522-528 (2000).

42. Mills, M., Meysick, K. C. \& O'Brien, A. D. Cytotoxic necrotizing factor type 1 of uropathogenic Escherichia coli kills cultured human uroepithelial 5637 cells by an apoptotic mechanism. Infect. Immun. 68, 5869-5880 (2000).

43. Johnson, D. E. et al. The role of cytotoxic necrotizing factor-1 in colonization and tissue injury in a murine model of urinary tract infection. FEMS Immunol. Med. Microbiol. 28, 37-41 (2000).

44. Rippere-Lampe, K. E., O'Brien, A. D., Conran, R. \& Lockman, H. A. Mutation of the gene encoding cytotoxic necrotizing factor type $1\left(\mathrm{cnf}_{1}\right)$ attenuates the virulence of uropathogenic Escherichia coli. Infect. Immun. 69, 3954-3964 (2001).

45. Parham, N. J. et al. PicU, a second serine protease autotransporter of uropathogenic Escherichia coli. FEMS Microbiol. Lett. 230, 73-83 (2004).

46. Guyer, D. M., Radulovic, S., Jones, F. E. \& Mobley, H. L. Sat, the secreted autotransporter toxin of uropathogenic Escherichia coli, is a vacuolating cytotoxin for bladder and kidney epithelial cells. Infect. Immun. 70, 4539-4546 (2002).

47. Heimer, S. R., Rasko, D. A., Lockatell, C. V., Johnson, D. E. \& Mobley, H. L. Autotransporter genes pic and tsh are associated with Escherichia coli strains that cause acute pyelonephritis and are expressed during urinary tract infection. Infect. Immun. 72, 593-597 (2004).

48. Lane, M. C. et al. Role of motility in the colonization of uropathogenic Escherichia coli in the urinary tract. Infect. Immun. 73, 7644-7656 (2005).

49. Wright, K. J., Seed, P. C. \& Hultgren, S. J. Uropathogenic Escherichia coli flagella aid in efficient urinary tract colonization. Infect. Immun. 73, 7657-7668 (2005).

50. Snyder, J. A. et al. Transcriptome of uropathogenic Escherichia coli during urinary tract infection. Infect. Immun. 72, 6373-6381 (2004).

51. Lane, M. C., Alteri, C. J., Smith, S. N. \& Mobley, H. L. Expression of flagella is coincident with uropathogenic Escherichia coli ascension to the upper urinary tract. Proc. Natl Acad. Sci. USA 104, 16669-16674 (2007).

52. Hagan, E. C. \& Mobley, H. L. Haem acquisition is facilitated by a novel receptor Hma and required by uropathogenic Escherichia coli for kidney infection. Mol. Microbiol. 71, 79-91 (2009).

53. Torres, A. G., Redford, P., Welch, R. A. \& Payne, S. M. TonB-dependent systems of uropathogenic Escherichia coli: aerobactin and heme transport and TonB are required for virulence in the mouse. Infect. Immun. 69, 6179-6185 (2001).

54. Johnson, J. R. et al. The IrgA homologue adhesin Iha is an Escherichia coli virulence factor in murine urinary tract infection. Infect. Immun. 73, 965-971 (2005).

55. Russo, T. A., Carlino, U. B. \& Johnson, J. R. Identification of a new iron-regulated virulence gene, ire $A$, in an extraintestinal pathogenic isolate of Escherichia coli. Infect. Immun. 69, 6209-6216 (2001)

56. Russo, T. A. et al. Iron functions as a siderophore receptor and is a urovirulence factor in an extraintestinal pathogenic isolate of Escherichia coli. Infect. Immun. 70 , 7156-7160 (2002).

57. Sabri, M., Houle, S. \& Dozois, C. M. Roles of the extraintestinal pathogenic Escherichia coli ZnuACB and ZupT zinc transporters during urinary tract infection. Infect. Immun. 77, 1155-1164 (2009).

58. Goetz, D. H. et al. The neutrophil lipocalin NGAL is a bacteriostatic agent that interferes with siderophore-mediated iron acquisition. Mol. Cell 10, 1033-1043 (2002).

59. Fischbach, M. A. et al. The pathogenassociated iroA gene cluster mediates bacterial evasion of lipocalin 2. Proc. Natl Acad. Sci. USA 103, 16502-16507 (2006).

60. Smith, K. D. Iron metabolism at the host pathogen interface: lipocalin 2 and the pathogen-associated iroA gene cluster. Int. J. Biochem. Cell. Biol. 39, 1776-1780 (2007).

61. Cirl, C. et al. Subversion of Toll-like receptor signaling by a unique family of bacterial Toll/ interleukin-1 receptor domain-containing proteins. Nat. Med. 14, 399-406 (2008).

62. Billips, B. K., Schaeffer, A. J. \& Klumpp, D. J. Molecular basis of uropathogenic Escherichia coli evasion of the innate immune response in the bladder. Infect. Immun. 76, 3891-3900 (2008).

63. Hunstad, D. A., Justice, S. S., Hung, C. S., Lauer, S. R. \& Hultgren, S. J. Suppression of bladder epithelial cytokine responses by uropathogenic Escherichia coli. Infect. Immun. 73, 3999-4006 (2005).

64. Johnson, J. R., Clabots, C. \& Rosen, H. Effect of inactivation of the global oxidative stress regulator oxyR on the colonization ability of Escherichia coli 01: $\mathrm{K} 1: \mathrm{H} 7$ in a mouse model of ascending urinary tract infection. Infect. Immun. 74, 461-468 (2006).

65. Bower, J. M. \& Mulvey, M. A. Polyaminemediated resistance of uropathogenic Escherichia coli to nitrosative stress. J. Bacteriol. 188, 928-933 (2006).

66. Kulesus, R. R., Diaz-Perez, K., Slechta, E. S. Eto, D. S. \& Mulvey, M. A. Impact of the RNA chaperone $\mathrm{Hfq}$ on the fitness and virulence potential of uropathogenic Escherichia coli. Infect. Immun. 76, 3019-3026 (2008).

67. Svensson, L., Marklund, B. I., Poljakovic, M. \& Persson, K. Uropathogenic Escherichia coli and tolerance to nitric oxide: the role of flavohemoglobin. J. Urol. 175, 749-753 (2006).

68. Lloyd, A. L., Smith, S. N., Eaton, K. A. \& Mobley, H. L. Uropathogenic Escherichia coli suppresses the host inflammatory response via pathogenicity island genes sis $A$ and sis $B$. Infect. Immun. 77, 5322-5333 (2009).

69. Li, K., Feito, M. J., Sacks, S. H. \& Sheerin, N. S. CD46 (membrane cofactor protein) acts as a human epithelial cell receptor for internalization of opsonized uropathogenic Escherichia coli. J. Immunol. 177, 2543-2551 (2006).
70. Mysorekar, I. U. \& Hultgren, S. J. Mechanisms of uropathogenic Escherichia coli persistence and eradication from the urinary tract. Proc. Nat Acad. Sci. USA 103, 14170-14175 (2006).

71. Anderson, G. G. et al. Intracellular bacterial biofilm-like pods in urinary tract infections. Science 301, 105-107 (2003).

72. Rosen, D. A., Hooton, T. M., Stamm, W. E., Humphrey, P. A. \& Hultgren, S. J. Detection of intracellular bacterial communities in human urinary tract infection. PLoS Med. 4, e329 (2007).

73. Anderson, G. G., Martin, S. M. \& Hultgren, S. J. Host subversion by formation of intracellular bacterial communities in the urinary tract. Microbes Infect. 6, 1094-1101 (2004).

74. Justice, S. S. et al. Differentiation and developmental pathways of uropathogenic Escherichia coli in urinary tract pathogenesis. Proc. Natl Acad. Sci. USA 101, 1333-1338 (2004).

75. Rocha, S. P., Pelayo, J. S. \& Elias, W. P. Fimbriae of uropathogenic Proteus mirabilis. FEMS Immunol. Med. Microbiol. 51, 1-7 (2007).

76. Bahrani, F. K., Johnson, D. E., Robbins, D. \& Mobley, H. L. Proteus mirabilis flagella and MR/P fimbriae: isolation, purification, $\mathrm{N}$-terminal analysis, and serum antibody response following experimental urinary tract infection. Infect. Immun. 59, 3574-3580 (1991).

77. Jansen, A. M., Lockatell, V., Johnson, D. E. \& Mobley, H. L. Mannose-resistant Proteus-like fimbriae are produced by most Proteus mirabilis strains infecting the urinary tract, dictate the in vivo localization of bacteria, and contribute to biofilm formation. Infect. Immun. 72 , 7294-7305 (2004).

78. Li, X., Johnson, D. E. \& Mobley, H. L. Requirement of $\mathrm{MrpH}$ for mannose-resistan Proteus-like fimbria-mediated hemagglutination by Proteus mirabilis. Infect. Immun. 67, 2822-2833 (1999).

79. Bahrani, F. K. et al. Construction of an MR/P fimbrial mutant of Proteus mirabilis: role in virulence in a mouse model of ascending urinary tract infection. Infect. Immun. 62, 3363-3371 (1994).

80. Li, X., Lockatell, C. V., Johnson, D. E. \& Mobley, H. L. Identification of Mrpl as the sole recombinase that regulates the phase variation of MR/P fimbria, a bladder colonization factor of uropathogenic Proteus mirabilis. Mol. Microbiol. 45, 865-874 (2002).

81. Altman, E. et al. Galectin-3-mediated adherence of Proteus mirabilis to Madin-Darby canine kidney cells. Biochem. Cell. Biol. 79, 783-788 (2001).

82. Lee, K. K., Harrison, B. A., Latta, R. \& Altman, E. The binding of Proteus mirabilis nonagglutinating fimbriae to ganglio-series asialoglycolipids and lactosyl ceramide. Can. J. Microbiol. 46, 961-966 (2000)

83. Wray, S. K., Hull, S. I., Cook, R. G., Barrish, J. \& Hull, R. A. Identification and characterization of a uroepithelial cell adhesin from a uropathogenic isolate of Proteus mirabilis. Infect. Immun. 54, 43-49 (1986).

84. Massad, G., Lockatell, C. V., Johnson, D. E. \& Mobley, H. L. Proteus mirabilis fimbriae: construction of an isogenic pmfA mutant and analysis of virulence in a CBA mouse model of ascending urinary tract infection. Infect. Immun. 62, 536-542 (1994).

85. Zunino, P. et al. Proteus mirabilis fimbriae (PMF) are important for both bladder and kidney colonization in mice. Microbiology 149 , 3231-3237 (2003).

86. Massad, G., Bahrani, F. K. \& Mobley, H. L. Proteus mirabilis fimbriae: identification, 
isolation, and characterization of a new ambienttemperature fimbria. Infect. Immun. $\mathbf{6 2}$, 1989-1994 (1994).

87. Zunino, P., Geymonat, L., Allen, A. G., LegnaniFajardo, C. \& Maskell, D. J. Virulence of a Proteus mirabilis ATF isogenic mutant is not impaired in a mouse model of ascending urinary tract infection. FEMS Immunol. Med. Microbiol. 29, 137-143 (2000).

88. Bijlsma, I. G., van Dijk, L., Kusters, J. G. \& Gaastra, W. Nucleotide sequences of two fimbrial major subunit genes, $p m p A$ and $u c a A$, from canine-uropathogenic Proteus mirabilis strains. Microbiology 141, 1349-1357 (1995).

89. Uphoff, T. S. \& Welch, R. A. Nucleotide sequencing of the Proteus mirabilis calciumindependent hemolysin genes ( $h p m A$ and $h p m B$ ) reveals sequence similarity with the Serratia marcescens hemolysin genes (sh/A and shIB). J. Bacteriol. 172, 1206-1216 (1990).

90. Welch, R. A. Identification of two different hemolysin determinants in uropathogenic Proteus isolates. Infect. Immun. 55, 2183-2190 (1987).

91. Alamuri, P. \& Mobley, H. L. A novel autotransporter of uropathogenic Proteus mirabilis is both a cytotoxin and an agglutinin. Mol. Microbiol. 68, 997-1017 (2008).

92. Alamuri, P., Eaton, K. A., HimpsI, S. D., Smith, S. N. \& Mobley, H. L. Vaccination with proteus toxic agglutinin, a hemolysinindependent cytotoxin in vivo, protects against Proteus mirabilis urinary tract infection. Infect. Immun. 77, 632-641 (2009).

93. Rather, P. N. Swarmer cell differentiation in Proteus mirabilis. Environ. Microbiol. 7, 1065-1073 (2005).

94. Jansen, A. M., Lockatell, C. V., Johnson, D. E. \& Mobley, H. L. Visualization of Proteus mirabilis morphotypes in the urinary tract: the elongated swarmer cell is rarely observed in ascending urinary tract infection. Infect. Immun. 71, 3607-3613 (2003).

95. Jones, B. V., Young, R., Mahenthiralingam, E. \& Stickler, D. J. Ultrastructure of Proteus mirabilis swarmer cell rafts and role of swarming in catheter-associated urinary tract infection. Infect. Immun. 72, 3941-3950 (2004).

96. Mobley, H. L. et al. Construction of a flagellumnegative mutant of Proteus mirabilis: effect on internalization by human renal epithelial cells and virulence in a mouse model of ascending urinary tract infection. Infect. Immun. 64, 5332-5340 (1996).

97. Zunino, P., Piccini, C. \& Legnani-Fajardo, C. Flagellate and non-flagellate Proteus mirabilis in the development of experimental urinary tract infection. Microb. Pathog. 16, 379-385 (1994).

98. Evanylo, L. P., Kadis, S. \& Maudsley, J. R. Siderophore production by Proteus mirabilis. Can. J. Microbiol. 30, 1046-1051 (1984).

99. Lima, A., Zunino, P., D'Alessandro, B. \& Piccini, C. An iron-regulated outer-membrane protein of Proteus mirabilis is a haem receptor that plays an important role in urinary tract infection and in in vivo growth. J. Med. Microbiol. 56, 1600-1607 (2007).

100. Drechsel, H., Thieken, A., Reissbrodt, R., Jung, G. \& Winkelmann, G. Alpha-keto acids are novel siderophores in the genera Proteus, Providencia, and Morganella and are produced by amino acid deaminases. J. Bacteriol. 175, 2727-2733 (1993).

101. Massad, G., Zhao, H. \& Mobley, H. L. Proteus mirabilis amino acid deaminase: cloning, nucleotide sequence, and characterization of aad. J. Bacteriol. 177, 5878-5883 (1995).
102. Nielubowicz, G. R., Smith, S. N. \& Mobley, H. L. Zinc uptake contributes to motility and provides a competitive advantage to Proteus mirabilis during experimental urinary tract infection. Infect. Immun. 78, 2823-2833 (2010).

103. Belas, R., Manos, J. \& Suvanasuthi, R. Proteus mirabilis ZapA metalloprotease degrades a broad spectrum of substrates, including antimicrobial peptides. Infect. Immun. 72, 5159-5167 (2004).

104. Senior, B. W., Loomes, L. M. \& Kerr, M. A. The production and activity in vivo of Proteus mirabilis IgA protease in infections of the urinary tract. J. Med. Microbiol. 35, 203-207 (1991).

105. Walker, K. E., Moghaddame-Jafari, S., Lockatell, C. V., Johnson, D. \& Belas, R. ZapA, the IgA-degrading metalloprotease of Proteus mirabilis, is a virulence factor expressed specifically in swarmer cells. Mol. Microbiol. 32 , 825-836 (1999).

106. Belas, R. \& Flaherty, D. Sequence and genetic analysis of multiple flagellin-encoding genes from Proteus mirabilis. Gene 148, 33-41 (1994).

107. Belas, R. Expression of multiple flagellinencoding genes of Proteus mirabilis. J. Bacteriol. 176, 7169-7181 (1994).

108. Murphy, C. A. \& Belas, R. Genomic rearrangements in the flagellin genes of Proteus mirabilis. Mol. Microbiol. 31, 679-690 (1999).

109. Zhao, H., Li, X., Johnson, D. E., Blomfield, I. \& Mobley, H. L. In vivo phase variation of MR/P fimbrial gene expression in Proteus mirabilis infecting the urinary tract. Mol. Microbiol. 23, 1009-1019 (1997).

110. Li, X. et al. Visualization of Proteus mirabilis within the matrix of urease-induced bladder stones during experimental urinary tract infection. Infect. Immun. 70, 389-394 (2002).

111. Thomas, W. E., Nilsson, L. M., Forero, M., Sokurenko, E. V. \& Vogel, V. Shear-dependent 'stick-and-roll' adhesion of type 1 fimbriated Escherichia coli. Mol. Microbiol. 53, 1545-1557 (2004).

112. Wu, X. R., Kong, X. P., Pellicer, A., Kreibich, G. \& Sun, T. T. Uroplakins in urothelial biology, function, and disease. Kidney Int. 75, 1153-1165 (2009).

113. Zhou, G. et al. Uroplakin la is the urothelial receptor for uropathogenic Escherichia coli: evidence from in vitro FimH binding. J. Cell. Sci. 114, 4095-4103 (2001).

114. Mulvey, M. A. et al. Induction and evasion of host defenses by type 1-piliated uropathogenic Escherichia coli. Science 282, 1494-1497 (1998).

115. Fukushi, Y., Orikasa, S. \& Kagayama, M. An electron microscopic study of the interaction between vesical epitherlium and $E$. coli. Invest. Urol. 17, 61-68 (1979).

116. Klumpp, D. J. et al. Uropathogenic Escherichia coli potentiates type 1 pilus-induced apoptosis by suppressing NF-kB. Infect. Immun. 69 , 6689-6695 (2001).

117. Sivick, K. E. \& Mobley, H. L. Waging war against uropathogenic Escherichia coli: winning back the urinary tract. Infect. Immun. 78, 568-585 (2010).

118. Wullt, B. et al. The host response to urinary tract infection. Infect. Dis. Clin. North Am. 17 279-301 (2003).

119. Chromek, M. et al. The antimicrobial peptide cathelicidin protects the urinary tract against invasive bacterial infection. Nat. Med. 12 636-641 (2006).

120. Morrison, G., Kilanowski, F., Davidson, D. \& Dorin, J. Characterization of the mouse beta defensin 1, Defb1, mutant mouse model. Infect. Immun. 70, 3053-3060 (2002).
121. Valore, E. V. et al. Human beta-defensin-1: an antimicrobial peptide of urogenital tissues. J. Clin. Invest. 101, 1633-1642 (1998).

122. Ganz, T. Iron in innate immunity: starve the invaders. Curr. Opin. Immunol. 21, 63-67 (2009).

123. Serafini-Cessi, F., Malagolini, N. \& Cavallone, D. Tamm-Horsfall glycoprotein: biology and clinical relevance. Am. J. Kidney Dis. 42, 658-676 (2003).

124. Raffi, H. S., Bates, J. M., Jr, Laszik, Z. \& Kumar, S. Tamm-horsfall protein protects against urinary tract infection by Proteus mirabilis. J. Urol. 181, 2332-2338 (2009).

125. Ingersoll, M. A., Kline, K. A., Nielsen, H. V. \& Hultgren, S. J. G-CSF induction early in uropathogenic Escherichia coli infection of the urinary tract modulates host immunity. Cell. Microbiol. 10, 2568-2578 (2008).

126. Sivick, K. E., Schaller, M. A., Smith, S. N. \& Mobley, H. L. The innate immune response to uropathogenic Escherichia coli involves IL-17A in a murine model of urinary tract infection. J. Immunol. 184, 2065-2075 (2010).

127. Hedges, S. et al. Uroepithelial cells are part of a mucosal cytokine network. Infect. Immun. 62, 2315-2321 (1994).

128. Schilling, J. D., Mulvey, M. A., Vincent, C. D., Lorenz, R. G. \& Hultgren, S. J. Bacterial invasion augments epithelial cytokine responses to Escherichia coli through a lipopolysaccharidedependent mechanism. J. Immunol. 166, 1148-1155 (2001)

129. Wullt, B. et al. P-fimbriae trigger mucosal responses to Escherichia coli in the human urinary tract. Cell. Microbiol. 3, 255-264 (2001).

130. Agace, W. W. The role of the epithelial cell in Escherichia coli induced neutrophil migration into the urinary tract. Eur. Respir. J. 9, 1713-1728 (1996).

131. Agace, W. W., Hedges, S. R., Ceska, M. \& Svanborg, C. Interleukin-8 and the neutrophil response to mucosal gram-negative infection. J. Clin. Invest. 92, 780-785 (1993).

132. Hang, L. et al. Macrophage inflammatory protein-2 is required for neutrophil passage across the epithelial barrier of the infected urinary tract. J. Immunol. 162, 3037-3044 (1999).

133. Haraoka, M. et al. Neutrophil recruitment and resistance to urinary tract infection. J. Infect. Dis. 180, 1220-1229 (1999).

134. Ragnarsdottir, B. et al. TLR- and CXCR1dependent innate immunity: insights into the genetics of urinary tract infections. Eur. J. Clin. Invest. 38 (Suppl. 2), 12-20 (2008).

135. Ashkar, A. A., Mossman, K. L., Coombes, B. K. Gyles, C. L. \& Mackenzie, R. FimH adhesin of type 1 fimbriae is a potent inducer of innate antimicrobial responses which requires TLR4 and type 1 interferon signalling. PLoS Pathog. 4, e1000233 (2008).

136. Schilling, J. D., Martin, S. M., Hung, C. S., Lorenz, R. G. \& Hultgren, S. J. Toll-like receptor 4 on stromal and hematopoietic cells mediates innate resistance to uropathogenic Escherichia coli. Proc. Natl Acad. Sci. USA 100, 4203-4208 (2003).

137. Patole, P. S. et al. Toll-like receptor-4: renal cells and bone marrow cells signal for neutrophil recruitment during pyelonephritis. Kidney Int. 68 2582-2587 (2005)

138. Frendeus, B. et al. Escherichia coli P fimbriae utilize the Toll-like receptor 4 pathway for cell activation. Mol. Microbiol. 40, 37-51 (2001).

139. Hedges, S., Svensson, M. \& Svanborg, C. Interleukin-6 response of epithelial cell lines to bacterial stimulation in vitro. Infect. Immun. 60 , 1295-1301 (1992). 
140. Hedlund, M. et al. P fimbriae-dependent, lipopolysaccharide-independent activation of epithelial cytokine responses. Mol. Microbiol. 33, 693-703 (1999).

141. Hedlund, M. et al. Type 1 fimbriae deliver an LPS- and TLR4-dependent activation signal to CD14-negative cells. Mol. Microbiol. 39, 542-552 (2001)

142. Mossman, K. L. et al. Cutting edge: FimH adhesin of type 1 fimbriae is a novel TLR4 ligand. J. Immunol. 181, 6702-6706 (2008).

143. Fischer, H., Yamamoto, M., Akira, S., Beutler, B. \& Svanborg, C. Mechanism of pathogen-specific TLR4 activation in the mucosa: fimbriae, recognition receptors and adaptor protein selection. Eur. J. Immunol. 36, 267-277 (2006).

144. Andersen-Nissen, E. et al. Cutting edge: TIr5 ${ }^{-/-}$mice are more susceptible to Escherichia coli urinary tract infection. J. Immunol. 178, 4717-4720 (2007).

145. Hayashi, F. et al. The innate immune response to bacterial flagellin is mediated by Toll-like receptor 5. Nature 410, 1099-1103 (2001).

146. Zhang, D. et al. A toll-like receptor that prevents infection by uropathogenic bacteria. Science 303, 1522-1526 (2004).

147. Thumbikat, P., Waltenbaugh, C., Schaeffer, A. J. \& Klumpp, D. J. Antigen-specific responses accelerate bacterial clearance in the bladder. J. Immunol. 176, 3080-3086 (2006).

148. Pearsall, N. N. \& Sherris, J. C. The demonstration of specific urinary anti-bodies in urinary tract infections caused by Gram-negative bacilli. J. Pathol. Bacteriol. 91, 589-595 (1966).

149. Eden, C. S., Hanson, L. A., Jodal, U., Lindberg, U. \& Akerlund, A. S. Variable adherence to normal human urinary-tract epithelial cells of Escherichia coli strains associated with various forms of urinary-tract infection. Lancet 1, 490-492 (1976).

150. Svanborg-Eden, C. \& Svennerholm, A. M. Secretory immunoglobulin $A$ and $G$ antibodies prevent adhesion of Escherichia coli to human urinary tract epithelial cells. Infect. Immun. 22, 790-797 (1978).

151. Trinchieri, A. et al. Secretory immunoglobulin A and inhibitory activity of bacterial adherence to epithelial cells in urine from patients with urinary tract infections. Urol. Res. 18, 305-308 (1990).

152. Svanborg, C. et al. Uropathogenic Escherichia coli as a model of host-parasite interaction. Curr. Opin. Microbiol. 9, 33-39 (2006).

153. Lomberg, H., Jodal, U., Eden, C. S., Leffler, H. \& Samuelsson, B. P1 blood group and urinary tract infection. Lancet 1, 551-552 (1981).

154. Hagberg, L. et al. Difference in susceptibility to gram-negative urinary tract infection between $\mathrm{C} 3 \mathrm{H} / \mathrm{HeJ}$ and $\mathrm{C} 3 \mathrm{H} / \mathrm{HeN}$ mice. Infect. Immun. 46, 839-844 (1984)

155. Goluszko, P. et al. Vaccination with purified Dr Fimbriae reduces mortality associated with chronic urinary tract infection due to Escherichia coli bearing $\mathrm{Dr}$ adhesin. Infect. Immun. 73, 627-631 (2005).

156. Ragnarsdottir, B. et al. Reduced toll-like receptor 4 expression in children with asymptomatic bacteriuria. J. Infect. Dis. 196, 475-484 (2007).

157. Frendeus, B. et al. Interleukin 8 receptor deficiency confers susceptibility to acute experimental pyelonephritis and may have a human counterpart. J. Exp. Med. 192, 881-890 (2000).

158. Godaly, G., Hang, L., Frendeus, B. \& Svanborg, C. Transepithelial neutrophil migration is CXCR1 dependent in vitro and is defective in IL-8 receptor knockout mice. J. Immunol. 165, 5287-5294 (2000).
159. Hang, L., Frendeus, B., Godaly, G. \& Svanborg, C. Interleukin-8 receptor knockout mice have subepithelial neutrophil entrapment and renal scarring following acute pyelonephritis. J. Infect. Dis. 182, 1738-1748 (2000).

160. Lundstedt, A. C. et al. A genetic basis of susceptibility to acute pyelonephritis. PLOS ONE 2, e825 (2007)

161. Lundstedt, A. C. et al. Inherited susceptibility to acute pyelonephritis: a family study of urinary tract infection. J. Infect. Dis. 195, 1227-1234 (2007).

162. Johnson, J. R. in Urinary Tract Infections: Molecular Pathogenesis and Clinical Management (eds Mobley, H. L. T. \& Warren, J. W.) 95-118 (ASM Press, Washington, DC, 1996).

163. Svensson, M. et al. Glycolipid depletion in antimicrobial therapy. Mol. Microbiol. 47, 453-461 (2003).

164. Bishop, B. L. et al. Cyclic AMP-regulated exocytosis of Escherichia coli from infected bladder epithelial cells. Nat. Med. 13, 625-630 (2007).

165. Bouckaert, J. et al. Receptor binding studies disclose a novel class of high-affinity inhibitors of the Escherichia coli FimH adhesin. Mol. Microbiol. 55, 441-455 (2005).

166. Thankavel, K. et al. Localization of a domain in the FimH adhesin of Escherichia coli type 1 fimbriae capable of receptor recognition and use of a domain-specific antibody to confer protection against experimental urinary tract infection. J. Clin. Invest. 100, 1123-1136 (1997).

167. Lilly, J. D. \& Parsons, C. L. Bladder surface glycosaminoglycans is a human epithelial permeability barrier. Surg. Gynecol. Obstet. 171, 493-496 (1990).

168. Maki, D. G. \& Tambyah, P. A. Engineering out the risk for infection with urinary catheters. Emerg. Infect. Dis. 7, 342-347 (2001).

169. Munasinghe, R. L., Yazdani, H., Siddique, M. \& Hafeez, W. Appropriateness of use of indwelling urinary catheters in patients admitted to the medical service. Infect. Control Hosp. Epidemiol. 22, 647-649 (2001).

170. Stickler, D. J., Jones, G. L. \& Russell, A. D. Control of encrustation and blockage of Foley catheters. Lancet 361, 1435-1437 (2003).

171. Hull, R. et al. Urinary tract infection prophylaxis using Escherichia coli 83972 in spinal cord injured patients. J. Urol. 163, 872-877 (2000).

172. Sabbuba, N. A. et al. Genotyping demonstrates that the strains of Proteus mirabilis from bladder stones and catheter encrustations of patients undergoing long-term bladder catheterization are identical. J. Urol. 171, 1925-1928 (2004).

173. Bauer, H. W. et al. A long-term, multicenter, double-blind study of an Escherichia coli extract $(\mathrm{OM}-89)$ in female patients with recurrent urinary tract infections. Eur. Urol. 47, 542-548 (2005).

174. Hopkins, W. J., Elkahwaji, J., Beierle, L. M., Leverson, G. E. \& Uehling, D. T. Vaginal mucosal vaccine for recurrent urinary tract infections in women: results of a phase 2 clinical trial. J. Urol. 177, 1349-1353 (2007).

175. Sivick, K. E. \& Mobley, H. L. An “omics" approach to uropathogenic Escherichia coli vaccinology. Trends Microbiol. 17, 431-432 (2009).

176. Alteri, C. J., Hagan, E. C., Sivick, K. E., Smith, S. N. \& Mobley, H. L. Mucosal immunization with iron receptor antigens protects against urinary tract infection. PLoS Pathog. 5, e1000586 (2009).

177. Johnson, D. E. et al. Serum immunoglobulin response and protection from homologous challenge by Proteus mirabilis in a mouse model of ascending urinary tract infection. Infect. Immun. 67, 6683-6687 (1999).

178. Li, X. \& Mobley, H. L. Vaccines for Proteus mirabilis in urinary tract infection. Int. J. Antimicrob. Agents 19, 461-465 (2002).

179. Moayeri, N., Collins, C. M. \& O'Hanley, P. Efficacy of a Proteus mirabilis outer membrane protein vaccine in preventing experimental Proteus pyelonephritis in a BALB/c mouse model. Infect. Immun. 59, 3778-3786 (1991).

180. Scavone, P. et al. Intranasal immunisation with recombinant Lactococcus lactis displaying either anchored or secreted forms of Proteus mirabilis MrpA fimbrial protein confers specific immune response and induces a significant reduction of kidney bacterial colonisation in mice. Microbes Infect. 9, 821-828 (2007).

181. Pellegrino, R., Galvalisi, U., Scavone, P., Sosa, V. \& Zunino, P. Evaluation of Proteus mirabilis structural fimbrial proteins as antigens against urinary tract infections. FEMS Immunol. Med. Microbiol. 36, 103-110 (2003).

182. Li, X. et al. Use of translational fusion of the $\mathrm{MrpH}$ fimbrial adhesin-binding domain with the cholera toxin A2 domain, coexpressed with the cholera toxin B subunit, as an intranasal vaccine to prevent experimental urinary tract infection by Proteus mirabilis. Infect. Immun. 72, 7306-7310 (2004).

183. Nielubowicz, G. R., Smith, S. N. \& Mobley, H. L. Outer membrane antigens of the uropathogen Proteus mirabilis recognized by the humoral response during experimental murine urinary tract infection. Infect. Immun. 76, 4222-4231 (2008).

184. Serruto, D., Serino, L., Masignani, V. \& Pizza, M Genome-based approaches to develop vaccines against bacterial pathogens. Vaccine $\mathbf{2 7}$, 3245-3250 (2009).

185. Abraham, J. M., Freitag, C. S., Clements, J. R. \& Eisenstein, B. I. An invertible element of DNA controls phase variation of type 1 fimbriae of Escherichia coli. Proc. Natl Acad. Sci. USA 82, 5724-5727 (1985).

186. Klemm, P. Two regulatory fim genes, fimB and fimE, control the phase variation of type 1 fimbriae in Escherichia coli. EMBO J. 5, 1389-1393 (1986).

187. Bryan, A. et al. Regulation of type 1 fimbriae by unlinked FimB- and FimE-like recombinases in uropathogenic Escherichia coli strain CFT073. Infect. Immun. 74, 1072-1083 (2006).

188. Lane, M. C., Li, X., Pearson, M. M., Simms, A. N. \& Mobley, H. L. Oxygen-limiting conditions enrich for fimbriate cells of uropathogenic Proteus mirabilis and Escherichia coli. J. Bacteriol. 191 1382-1392 (2009).

189. Li, X., Rasko, D. A., Lockatell, C. V., Johnson, D. E. \& Mobley, H. L. Repression of bacterial motility by a novel fimbrial gene product. EMBO J. 20, 4854-4862 (2001).

190. Pearson, M. M. \& Mobley, H. L. Repression of motility during fimbrial expression: identification of $14 \mathrm{mrpJ}$ gene paralogues in Proteus mirabilis. Mol. Microbiol. 69, 548-558 (2008).

191. Simms, A. N. \& Mobley, H. L. PapX, a P fimbrial operon-encoded inhibitor of motility in uropathogenic Escherichia coli. Infect. Immun. 76, 4833-4841 (2008).

\section{Acknowledgments}

We sincerely apologize to authors whose important work could not be included in this article owing to space limitations. We would like to thank Erin Hagan, Melanie Pearson, Patrick Vigil, and Kelsey Sivick for thoughtful discussions. This work was supported in part by Public Health Service Grants Al43363 and Al059722 from the National Institutes of Health. 